\title{
Association of Intron Microsatellite Instability and Exon Mutational Profile of TP53 in Human Gastric Cancers
}

\author{
XUEYUN HUO, XIAOQIN XIAO, SHUANGYUE ZHANG, DESHAN ZHOU and ZHENWEN CHEN \\ School of Basic Medical Sciences, Capital Medical University, \\ Beijing Key Laboratory of Cancer Invasion \& Metastasis Research, Beijing, P.R. China
}

\begin{abstract}
Background/Aim: Microsatellite instability (MSI) is a hallmark of genomic instability. In gastric cancer $(G C)$, MSI phenotype is an important molecular subgroup that is often closely correlated with elevated mutation rates on the whole genome level. However, on a single gene level, it is still unknown whether the MSI status of a gene is correlated with the mutational profile of the gene itself. Materials and Methods: We analyzed intron MSI status and exon mutational profile of TP53 through short tandem repeat (STR) scanning and direct sequencing respectively in gastric cancers and their matched normal tissues. Results: MSI status of the TP53 intron was significantly associated with the mutational profile of seven TP53 exon positions $(p=0.0416)$, male patients ( $p=0.0095)$, and drinking $(p=0.0474)$, and showed a mild correlation with longer survival time $(p=0.0584)$ and increasing age ( $p=0.0611)$. Conclusion: TP53 exons tended to mutation in the status of TP53 intron MSI.
\end{abstract}

Microsatellite (MS) repeating sequences composed of 1-6 base pairs (bp), are characterized by highly polymorphic abundance within a genome and enhanced mutability. Based on these characteristics, microsatellites are widely used as an important class of DNA markers in the detection of genomic mutations (1). Microsatellite instability (MSI) which presented as loss or gain of repeats within a reiterative motif is one of the major forms of genomic instability in cancer. Theoretically, MSI is a harmful event to genomic stability and known to be the early steps in tumorigenesis, but interestingly, although the underlying mechanism remains

Correspondence to: Zhenwen Chen or Deshan Zhou, School of Basic Medical Sciences, Capital Medical University, Beijing Key Laboratory of Cancer Invasion \& Metastasis Research, Xitoutiao No.10, Youwai Street, Fengtai District, Beijing 100069, P.R. China. e-mail: czwen@ccmu.edu.cn or zhouds08@ccmu.edu.cn

Key Words: Microsatellite instability (MSI), TP53 mutation, gastric cancers. ambiguous, a large number of studies have shown that MSI phenotype often related to a favorable prognosis that suggested MSI is a protective factor for the survival of certain cancers (2-4).

Gastric cancer (GC) is one of the most common cancers and the world's third leading cause of cancer deaths. Due to the high heterogeneity, gastric cancers were newly classified into four subtypes through a comprehensive molecular characterization: tumors positive for Epstein-Barr virus; microsatellite unstable tumors; genomically stable tumors; and tumors with chromosomal instability. MSI-positive GCs often show elevated mutation rates, including mutations of genes involved in tumor development (5). So far, research into the relationship between mutational profile and MSI status generally focussed on the whole genome level, rarely do studies investigated this relationship on a single gene level. Therefore, whether the MSI status of a single gene will influence the stability of the gene itself, especially its exons, is still unknown.

TP53 is one of the best studied tumor suppressor genes and is considered to be the 'guardian of the genome' for it is involved in maintaining genomic integrity. Normally, TP53 is present at low levels in the cell, but dramatically elevated in response to cellular stresses such as DNA damage. To prevent potentially harmful damage triggered by aberrant cell proliferation, TP53 transcriptionally activates numerous genes involved in various biological functions including cell cycle arrest, apoptosis or senescence (6). From analyzing genomic data from 4,994 tumors across 18 cancer types, Yu Liu et al., confirmed that mutation and/or deletion of the TP53 tumor suppressor gene was identified in approximately $\sim 50 \%$ of all human cancers which is consistent with previous indications (7). However, most previous studies were limited to TP53 exon alterations, and there is little work on the correlation of exon and intronic MS polymorphisms in gastric cancer. Herein, we evaluated the mutational profiles of TP53 exons in TP53intron MSI and MSS group separately, and further explored their association with clinicopathological characteristics in gastric cancers. These analyses delineated the correlation 
Table I. The primers of TP53 exon 1-11.

\begin{tabular}{|c|c|c|c|}
\hline Exon & Primer sequence & Product size (bp) & Annealing temperature $\left({ }^{\circ} \mathrm{C}\right)$ \\
\hline \multirow[t]{2}{*}{ Exon 1} & F: 5-GATGGGATTGGGGTTTTCCCCT & 219 & 60 \\
\hline & R: 5-GCCCGTGACTCAGAGAGGAC & & \\
\hline \multirow[t]{2}{*}{ Exon 2} & F: 5-GTGTCTCATGCTGGATCCCC & 299 & 58 \\
\hline & R: 5-CCAGCCCAACCCTTGTCCTT & & \\
\hline \multirow[t]{2}{*}{ Exon 3} & F: 5-TCAGATCCTAGCGTCGAGCC & 800 & 57 \\
\hline & R: 5-CTGAGGGTGTGATGGGATGG & & \\
\hline \multirow[t]{2}{*}{ Exon 4} & F: 5-CAGCCTGGGTAACATGATGAA & 624 & 58 \\
\hline & R: 5-GAGGAATCAGAGGCCTGGGGA & & \\
\hline \multirow[t]{2}{*}{ Exon 5} & F: 5-AGCTGGGGCTGGAGAGACGA & 307 & 58 \\
\hline & R: 5-CATGGGGTTATAGGGAGGTCAA & & \\
\hline \multirow[t]{2}{*}{ Exon 6} & F: 5-AGTCCCAGCTACTCGGGAGG & 566 & 57 \\
\hline & R: 5-CCCTTGTCCTTTCTGGAGCCTAAG & & \\
\hline \multirow[t]{2}{*}{ Exon 7} & F: 5-ТCСАТАСТАСТАСССАТССАССТC & 645 & 57 \\
\hline & R: 5-AATTGCAGGTAAAACAGTCAAGAA & & \\
\hline \multirow[t]{2}{*}{ Exon 8} & F: 5-AAGCAAGCAGGACAAGAAGC & 290 & 56 \\
\hline & R: 5-TTTGAGGCATCACTGCCCCC & & \\
\hline \multirow[t]{2}{*}{ Exon 9} & F: 5-AGTGATGCCTCAAAGACAATGG & 278 & 56 \\
\hline & R: 5-GCAGGCTAGGCTAAGCTATGATGTT & & \\
\hline \multirow[t]{2}{*}{ Exon 10} & F: 5-TAGGTACTTGAAGTGCAGTTTCTAC & 340 & 56 \\
\hline & R: 5-CCTTTGACCATGAAGGCAGGA & & \\
\hline \multirow[t]{2}{*}{ Exon 11-1 } & F: 5-GCACAGACCCTCTCACTCAT & 690 & 56 \\
\hline & R: 5-AACTACCAACCCACCGACCA & & \\
\hline \multirow[t]{2}{*}{ Exon 11-2 } & F: 5-GTCTAGAACTTGACCCCCTT & 722 & 56 \\
\hline & R: 5-CACCCCTCAGACACACAGGT & & \\
\hline
\end{tabular}

between exon mutations and intronic MSI in TP53, and offer additional insight into TP53 features that may relate to the development of gastric cancer.

\section{Materials and Methods}

Patients. In this study, we analyzed 90 gastric cancer tissues and their matched normal tissues which were collected from patients with primary gastric cancer. The management of the tissue depository, the usage of the tissues and associated clinicopathological data were approved by the institutional review board of the Beijing Friendship Hospital.

Genomic DNA was extracted from gastric cancer tissues and their matched normal tissues, using a standard phenol-chloroform extraction and ethanol precipitation method, as previously described (8). The DNA samples were then quantitated by measuring the A260/A280 value with a microplate absorbance reader (Bio-Rad 680 , USA), and further evaluated by agarose gel electrophoresis. The DNA samples were diluted to a concentration of $100 \mathrm{ng} / \mu \mathrm{L}$ and stored at $-20^{\circ} \mathrm{C}$ for later use as templates in polymerase chain reactions (PCRs).

Microsatellite analysis. Here, we selected a microsatellite locus in intron 1 of the tumor suppressor gene TP53 (referred to as $T P 53 A L U$ ), the repeat unit is (AAAAT) and the designed primers as follows: 5'-GGCAATAAGAGCTGAGACTCC-3' (sense) and 5'-GACAAAACATCCCCTACCAAA-3' (antisense). To perform STR scanning efficiently, the forward primer of the locus was tagged at the 5' end with a fluorescent marker. The PCR amplification was carried out in a $20 \mu \mathrm{l}$ mixture: $2 \mu \mathrm{l}$ of $10 \times$ buffer, $0.5 \mu \mathrm{mol} / \mathrm{L}$ of each primer, $125 \mu \mathrm{mol} / \mathrm{l} \mathrm{dNTP}(4 \times), 1.0 \mathrm{U}$ of Taq DNA polymerase, $1.5 \mathrm{mmol} / 1 \mathrm{MgCl}_{2}$, and $100 \mathrm{ng}$ of template DNA. The PCR was performed in a gradient thermal cycler (BIORAD Inc., Hercules, California, USA) in accordance with the following protocol: pre-denaturation at $94^{\circ} \mathrm{C}$ for $5 \mathrm{~min} ; 35$ cycles of denaturation at $94^{\circ} \mathrm{C}$ for $30 \mathrm{~s}$, annealing at $62^{\circ} \mathrm{C}$ for $30 \mathrm{~s}$, and extension at $72^{\circ} \mathrm{C}$ for $30 \mathrm{~s}$, followed by a final extension at $72^{\circ} \mathrm{C}$ for $7 \mathrm{~min}$. The amplification products were evaluated on $2 \%$ agarose gels stained with ethidium bromide and visualized using a UV transilluminator (Gel DocTM XR+, BIO-RAD Inc., Hercules, California, USA) to confirm if they were amplified successfully and correctly by PCR, and then the samples were carefully stored at $4^{\circ} \mathrm{C}$ for subsequent STR scanning. Fluorescently labeled PCR products were examined by ABI-3730XL DNA Analyzer system (PE Biosystems, USA). The peak height of the wave was determined using GeneMarker version 1.75. To verify the new alleles generated, PCR products were purified using an ABI BigDye Terminator v3.1 Cycle Sequencing Kit, cloned into the PMD18-T Vector (TAKARA), and then sequenced using an ABI 3730XL DNA Sequencer.

Mutation analysis of TP53 exons. Based on the MSI status of TP53 intron 1, we selected 24 pairs of stage III gastric cancers and the matched normal tissues (MSI, N=9; MSS, N=15). To search for nucleotide alterations of the TP53 gene, the primers were designed to cover exons 1-11 (Table I). PCR-sequencing was done using an ABI 3730XL DNA Sequencer. 
A

Type 1 (No.14)

Type 2 (No.43)
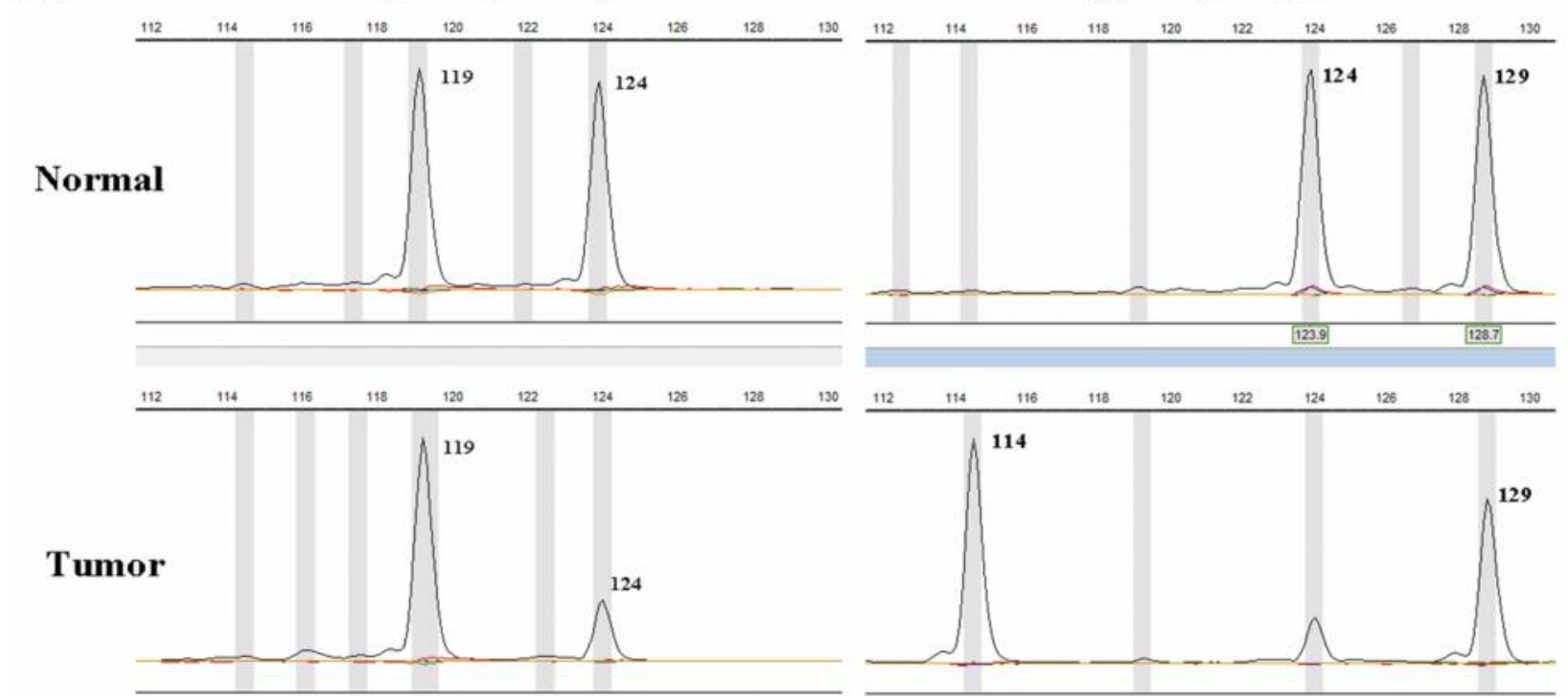

B

Tp53-1

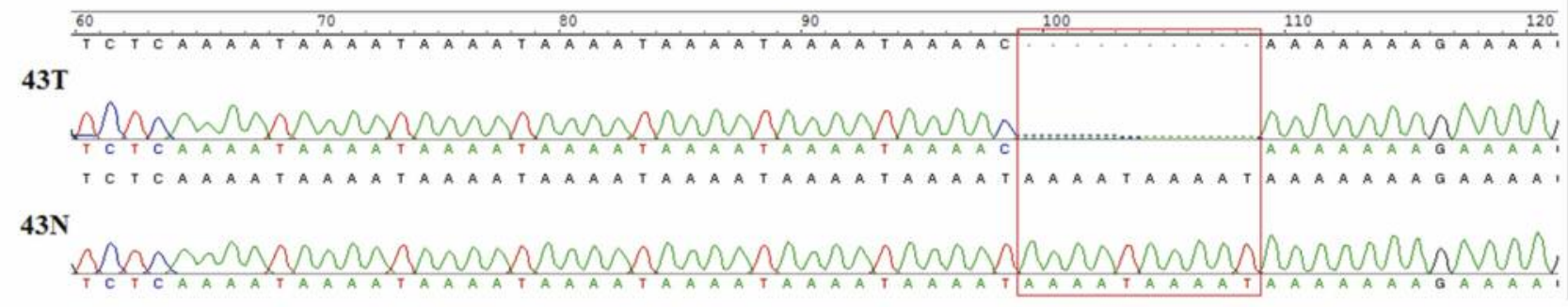

Figure 1. The MSI of TP53ALU detected in gastric cancers. A: The left row shows the Type 1 mutation. The allele size in the tumor tissues was changed from 119/124 bp to 119/119 bp. The right row shows the Type 2 mutation, with the allele size changed from $124 / 129 \mathrm{bp}$ to $114 / 129 \mathrm{bp}$. B: The sequencing result of MSI in TP53ALU. 43T, tumor tissue of case No.43; 43N, normal tissue of case No.43. Compared with normal tissue, TP53ALU showed deletion of two (AAAAT) repeat unit.

Statistical analysis. Statistical analysis was performed using SPSS 13.0. The association of MSI in the intron, the nucleotide alterations in exons of TP53 and the clinicopathological findings were analysed using a Pearson's Chi-square or Fisher exact test. A $p$-value $<0.05$ was considered statistically significant.

\section{Results}

MSI analysis of TP53 in the GCs by STR scanning. MSI and MSS status of TP53 in the 90 pairs of gastric cancers and their matched normal tissues were confirmed by the MSI analysis of the locus in TP53 intron 1 (TP53ALU) through STR scanning. We finally selected 24 pairs of stage III cancer cases for further study. Nine GCs showed alterations in the core sequence of TP53ALU. Two MSI patterns were observed. Type $1 \mathrm{MSI}$ is recorded as a loss of heterozygosity $(\mathrm{LOH})$ event which shows a complete or partial loss of one of the two heterozygote alleles, while Type 2 MSI often has one of the two alleles deletion and a novel allele appeared. Among the 9 MSI positive GCs, 8 of the mutations were Type $1 \mathrm{MSI}(8 / 9,88.9 \%)$, and only one sample $(1 / 9,11.1 \%)$ (No.43) was considered as Type 2 MSI (124/129bp to $114 / 129 b p)$ as there was a new $114 \mathrm{bp}$ allele (Figure 1A) $(p=0.0034)$. Then, the PCR product of sample No.43 was detected using clone sequencing, and the result confirmed the existence of the new 114bp allele (Figure 1B). Fortuitously, we found that microsatellite TP53ALU is highly polymorphic in normal human tissues, and we defined 9 different genotypes (Figure 2).

We performed further analysis of the clinicopathological characteristics by TP53ALU MSI status (Table II). TP53ALU MSI occurrence was vulnerable significantly in male patients rather than in female patients $(p=0.0095)$. The patients with a history of drinking alcohol were more prone to the TP53ALU 
Table II. Association of TP53 MSI with clinical characteristics

\begin{tabular}{|c|c|c|c|c|c|c|c|}
\hline & & MSI & MSS & $p$-Value & Mut & Non-Mut & $p$-Value \\
\hline Age & Mean & 68.3 & 60.5 & 0.0611 & 63.75 & 63.25 & 0.9113 \\
\hline \multirow{2}{*}{ Gender (No.) } & Male & 9 & 7 & 0.0095 & 6 & 10 & 0.6674 \\
\hline & Female & 0 & 8 & & 2 & 6 & \\
\hline \multirow[t]{2}{*}{ Alcohol Consumption } & Yes & 4 & 1 & 0.0474 & 3 & 2 & 0.2885 \\
\hline & No & 5 & 14 & & 5 & 14 & \\
\hline \multirow[t]{2}{*}{ Smoking } & Yes & 5 & 5 & 0.4028 & 4 & 6 & 0.6734 \\
\hline & No & 4 & 10 & & 4 & 10 & \\
\hline \multirow[t]{2}{*}{ Grade } & Well \& Moderate & 5 & 4 & 0.2119 & 3 & 6 & 1.0000 \\
\hline & Poorly & 4 & 11 & & 5 & 10 & \\
\hline \multirow[t]{2}{*}{ Type } & Adenocarcinoma & 7 & 8 & 0.3891 & 5 & 10 & 1.0000 \\
\hline & Others & 2 & 7 & & 3 & 6 & \\
\hline Survival (Month) & Median & 49.0 & 35.5 & 0.0584 & 58 & 37.75 & 0.0389 \\
\hline \multirow[t]{2}{*}{ MSI Status } & MSI & - & - & - & 5 & 4 & 0.0994 \\
\hline & MSS & - & - & - & 3 & 12 & \\
\hline
\end{tabular}

Table III. Mutations of TP53 exons detected in gastric cancers.

\begin{tabular}{|c|c|c|c|c|c|c|}
\hline Case & MSI Status & Exon 2 & Exon 3 & Exon 4 & Exon 6 & Exon 11 \\
\hline \multirow[t]{2}{*}{$\mathrm{T} 1$} & MSI & $140: C>C+G$ & - & - & - & - \\
\hline & & rs 1642785 & - & - & - & - \\
\hline \multirow[t]{2}{*}{$\mathrm{T} 13$} & MSI & - & - & - & $28: \mathrm{T}>\mathrm{A}+\mathrm{T}$ & - \\
\hline & & - & - & - & rs864622237 & - \\
\hline \multirow[t]{2}{*}{$\mathrm{T} 14$} & MSI & 140: $\mathrm{C}+\mathrm{G}>\mathrm{G}$ & - & 33: $\mathrm{T}+\mathrm{C}>\mathrm{C}$ & 87-89: CAT>del & - \\
\hline & & rs1642785 & - & rs1794287 & Unknown & - \\
\hline \multirow[t]{2}{*}{ T16 } & MSI & - & - & - & - & 48: $\mathrm{G}>\mathrm{G}+\mathrm{A}$ \\
\hline & & - & - & - & - & Unknown \\
\hline \multirow[t]{2}{*}{$\mathrm{T} 43$} & MSI & 140: $\mathrm{C}+\mathrm{G}>\mathrm{G}$ & - & - & - & - \\
\hline & & rs 1642785 & - & - & - & - \\
\hline \multirow[t]{2}{*}{$\mathrm{T} 26$} & MSS & - & - & - & - & 341: $\mathrm{G}>\mathrm{G}+\mathrm{A}$ \\
\hline & & - & - & - & - & rs17884306 \\
\hline \multirow[t]{2}{*}{ T74 } & MSS & - & 119: $\mathrm{C}+\mathrm{G}>\mathrm{G}$ & - & - & - \\
\hline & & - & rs1042522 & - & - & - \\
\hline \multirow[t]{2}{*}{$\mathrm{T} 85$} & MSS & 140: $\mathrm{C}+\mathrm{G}>\mathrm{del}$ & - & - & - & - \\
\hline & & rs 1642785 & & - & - & - \\
\hline
\end{tabular}

MSI than those who did not drink ( $p=0.0474)$. Compared to TP53ALU MSS patients, MSI patients presented with a slightly longer survival time $(p=0.0584)$. The older patients may be more likely to generate MSI at TP53ALU (Mean age, $68.3 v s$. 60.5, $p=0.0611)$. However, it seemed that TP53ALU MSI occurrence was not associated with smoking ( $p=0.4028)$, cancer grade $(p=0.2119)$ or type $(p=0.3891)$.

Mutation analysis of TP53 exons in the GCs by direct sequencing. Mutation analysis of TP53 exons was performed on 24 pairs of samples using direct sequencing. An overview of the mutations is shown in Table III. In brief, ten mutations that were distributed in 5 exons of TP53 were identified in $8(8 / 24,33.3 \%)$ GCs. Among the mutations, $119(\mathrm{C}+\mathrm{G}>\mathrm{G})$ in exon 3 (codon 72), $28(\mathrm{~T}>\mathrm{A}+\mathrm{T})$ (codon 234) and 87-89 (CAT<del) (codon 254) in exon 6 were observed in the coding sequence and the others $(70 \%, 7 / 10)$ were presented in the untranslated region of exons. Except $48(\mathrm{G}>\mathrm{G}+\mathrm{A})$ in exon 11 and 87-89 (CAT>del) in exon 6, the position of other mutations $(80 \%, 8 / 10)$ were defined as single nucleotide polymorphisms (SNP) loci and registered in the PubMed database. Position 140 in exon 4 was a hotspot that harbored $4(40 \%, 4 / 10)$ mutations and tumor T14 was considered to be the most unstable case carrying three mutations $(30 \%, 3 / 10)$.

Collectively, the mutations can be classified into 3 types (Figure 3). Type I mutation occurred where the genotype changed from homozygous to heterozygous, whereas Type II 


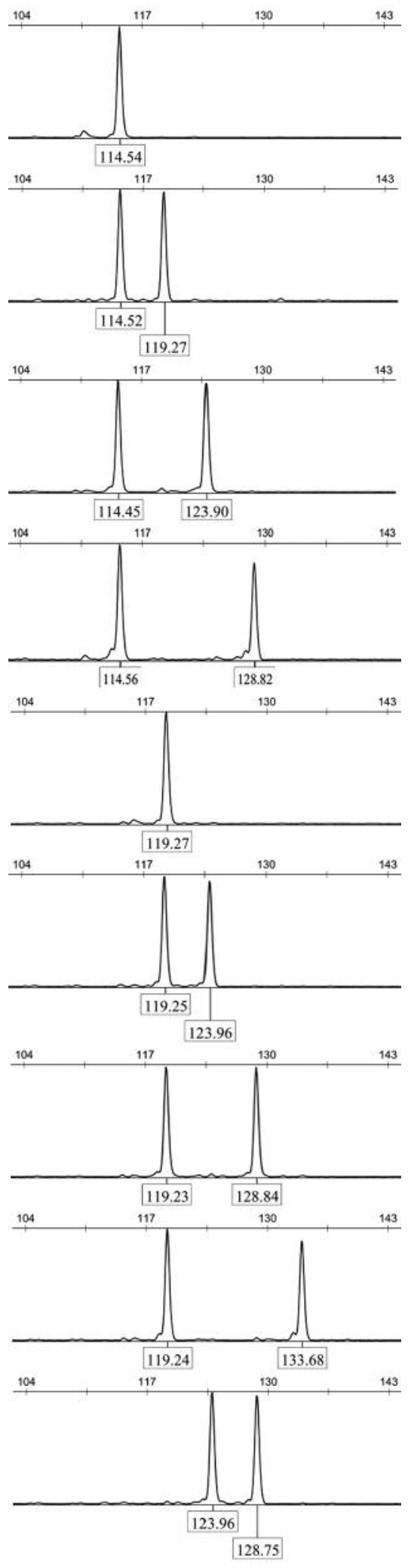

Figure 2. The 9 genotypes of TP53ALU in normal tissues. The genotypes from top were 114/114bp, 114/119 bp, 114/123 bp, 14/129 bp, 119/119 bp, 119/124 bp, 119/129 bp; 119/134 bp; 124/129 bp. mutation was from heterozygous to homozygous (LOH) and Type III mutation is in the form of one or more nucleotides deletion.

We further analyzed the correlation between TP53-exon mutation and TP53ALU MSI and clinicopathological aspects (Table II). Unexpectedly, patients with TP53-exon mutation presented a remarkably better outcome than those with no mutation $(p=0.0389)$. The results indicated that the rate of mutagenesis in the MSI group $(5 / 9,55.6 \%)$ was higher than that in the MSS group $(3 / 15,20 \%)$, but it was not significant $(p=0.0994)$. For the 7 alteration positions in 24 tumor tissues, the mutation rate in the MSI group ( 7 mutation/( 7 positions $\times 9$ MSI-tumor cases), $11.1 \%$ ) was significantly higher than that in the MSS group ( 3 mutation/(7 positions $\times 15$ MSS-tumor cases $), 2.9 \%)(p=0.0416) \quad$ (Figure 4). No correlation was found between TP53-exon mutation and other clinicopathological features.

\section{Discussion}

Generally, the MSI status, which is accessed by the Bethesda or its derived panel of microsatellites, represents the stability of the whole genome (9). However, whether the MSI status of a single gene will influence the stability of the gene itself especially its exons, is still unknown. The aim of this study was to investigate the exon mutational profile of TP53 in GCs along with the intron MSI status on TP53 itself, and to further analyze the relation with clinical features.

The microsatellite TP53ALU was initially found to be a polymorphism locus that had been frequently used as a marker in previous studies $(10,11)$. Consistently, we observed 9 genotypes of TP53ALU in normal tissues and confirmed that TP53ALU is a highly polymorphic pentanucleotide repeat microsatellite.

MSI-positive GCs were significantly associated with older age, female gender and a favorable outcome in advanced carcinoma (12). In our data, TP53ALU MSI GCs also showed some clinical characteristics such as a tendency for a longer survival time $(p=0.0584)$ and an older age $(p=0.0611)$ which were similar to earlier reports, and also a notable correlation with male patients $(p=0.0095)$ that was opposite to previous results. Moreover, TP53ALU MSI was found to be significantly related to alcohol consumption $(p=0.0474)$. These results indicated that MSI status of TP53ALU has a prognostic value in GCs.

It would be more accurate and reasonable to identify TP53-exon mutations in GCs by comparing the sequences with that found in matched normal tissues that were recorded in the Genebank database, as the sequences of TP53-exons we tested in normal tissues in this study, showed heterogeneity and differences from the database. Based on this, we finally defined 10 mutations in $8 \mathrm{GCs}$. Mutations at nucleotide 48 in exon 11 and nucleotides $85-87$ in exon 6 are 


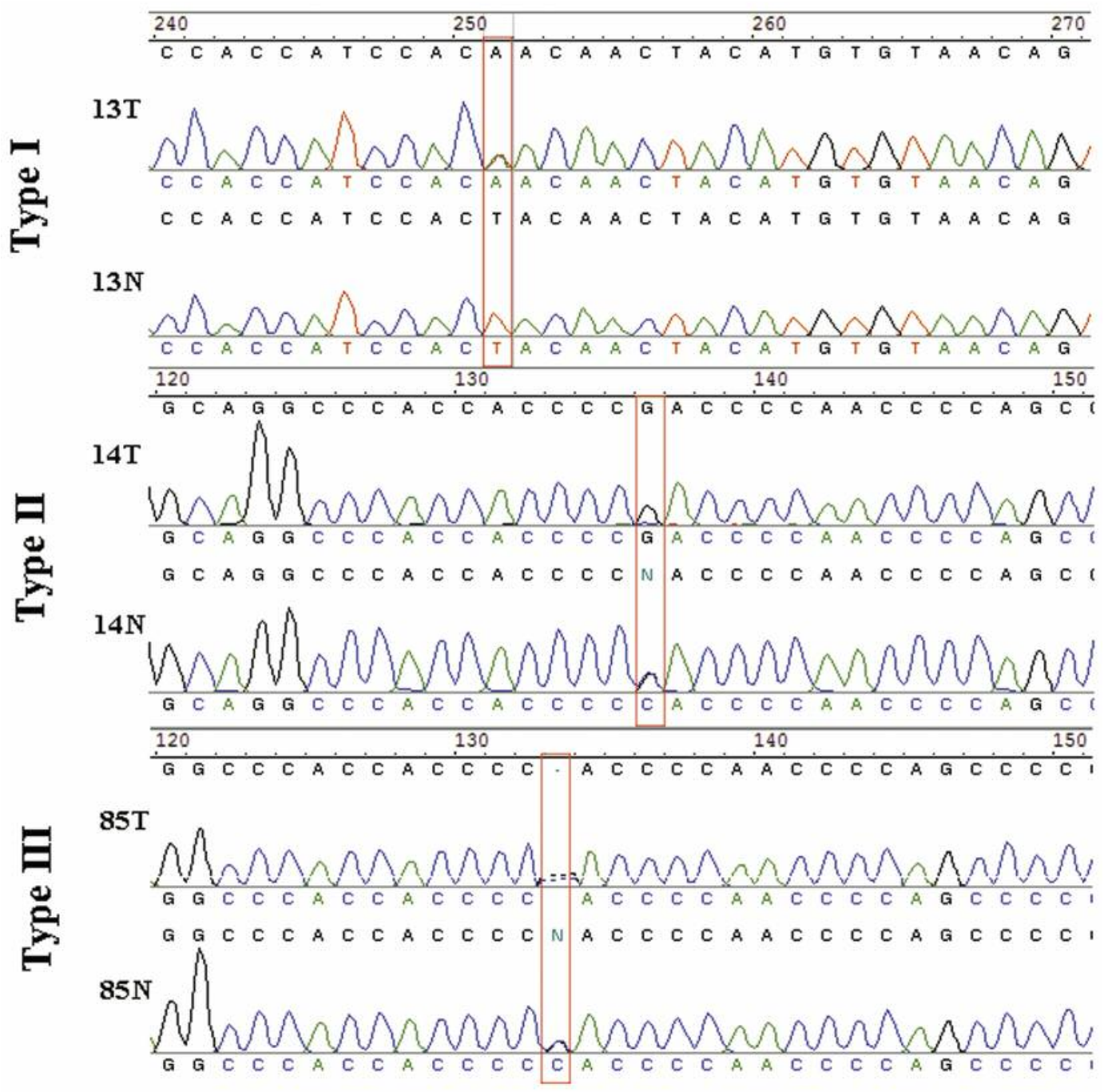

Figure 3. The mutation patterns of TP53 exons detected in gastric cancers. T, Tumor tissues; $N$, matched normal tissues. Type I mutation: the genotype of $13 T$ changed from T/T to T/A; Type II mutation: the genotype of $14 T$ changed from $C / G$ to $G / G$; Type III mutation: the genotype of $85 T$ changed from $\mathrm{C} / \mathrm{G}$ to deletion.

novel positions that have not been found to show alteration. Although most positions of the mutations (8/10) were known as SNP loci, the genotype of $140(\mathrm{del})$ in exon 2 has not been reported in previous studies.

A comprehensive genome-wide analysis of MSI in colorectal and endometrial cancer genomes showed a depletion of MSI events in coding regions, providing evidence for negative selection of mutations involving coding sequences (13). In the present study, three codingsequence mutations $119(\mathrm{C}+\mathrm{G}>\mathrm{G})$ in exon 3, $28(\mathrm{~T}>\mathrm{A}+\mathrm{T})$ and 87-89 $(\mathrm{CAT}<\mathrm{del})$ in exon 6 were identified, which caused amino acid alterations as follows: codon 72 Pro/Arg $>$ Arg/Arg, codon 234 Tyr/Tyr $>$ Asn/Tyr and codon 254 Ile/Ile $>$ del respectively.
Some of the mutations identified possess clinical significance. TP53 codon 72 has been proven to play an important role in many cancers and may affect the response to chemotherapy. For example, in patients with gastric cancer, the Arg/Pro genotype of TP53 codon 72 was significantly correlated with a lower response rate to paclitaxel plus cisplatin chemotherapy when compared to the Arg/Arg genotype; the Pro/Pro genotype was strongly associated with a lower response rate to paclitaxel plus cisplatin or paclitaxel plus capecitabine chemotherapy, and had notably shorter relapse-free survival and overall survival than patients with other genotypes when treated with 5-FU-based adjuvant chemotherapy in gastric cancer $(14,15)$. In breast cancer, allele Pro of TP53 codon 72 had 


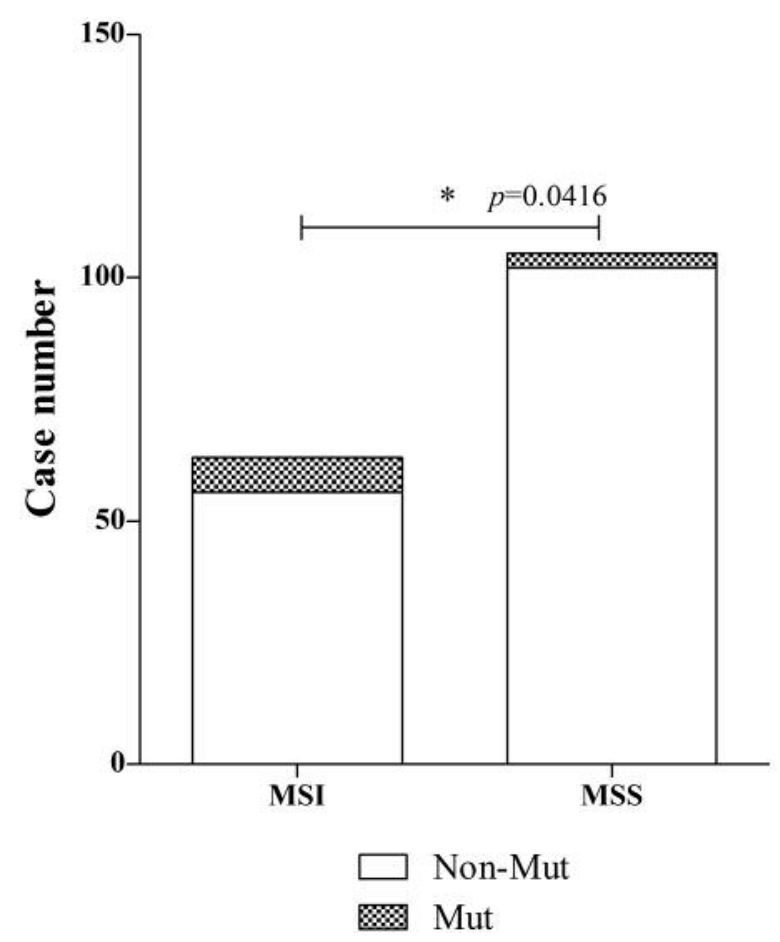

Figure 4. The mutation events in TP53ALU MSI and MSS group tumors regarding the 7 unstable positions. Mut: Mutation events; Non-Mut: non-mutation events of the 7 unstable positions.

a significant correlation with toxicity from 5 -fluorouracil plus cyclophosphamide-based neoadjuvant chemotherapy (16). Position 28 in exon 6 of TP53 (codon 234) was identified as a mutational hotspot as it was recurrently mutated across 14 cancer types (17). Mutation of codon 140 in exon 2 (rs1642785) and 341 in exon 11 (rs17884306) were likely benign alterations according to the records in the PubMed database.

Unexplainably, TP53-exon mutation was strongly related to a longer survival time $(p=0.0389)$, which was in conflict with the acknowledged viewpoint that most mutations result in the reduction of TP53 expression and consequently lead to the perturbations in p53 signaling pathways $(18,19)$.

Importantly, in accordance with the situations on the whole genome level, the results that most of the TP53-exon mutations were detected in TP53 MSI group suggested that TP53 exons tended to mutation in the status of TP53-intron MSI. These findings will provide new insights towards revealing the molecular features of TP53 in gastric cancers.

\section{Conflicts of Interest}

The Authors declare no conflicts of interest.

\section{Acknowledgements}

This work was supported by National Science Foundation of China (No. 31372272) and Support Project of High-level Teachers in Beijing Municipal Universities in the Period of 13th Five-year Plan (IDHT20170516).

\section{References}

1 Tautz D: Hypervariability of simple sequences as a general source for polymorphic DNA markers. Nucleic Acids Res 17: 6463-6471, 1989.

2 Hause RJ, Pritchard CC, Shendure J and Salipante SJ: Classification and characterization of microsatellite instability across 18 cancer types. Nat Med 22: 1342-1350, 2016.

3 Guastadisegni C, Colafranceschi M, Ottini L and Dogliotti E: Microsatellite instability as a marker of prognosis and response to therapy: a meta-analysis of colorectal cancer survival data. Eur J Cancer 46: 2788-2798, 2010.

4 Fang WL, Chang SC, Lan YT, Huang KH, Chen JH, Lo SS, Hsieh $\mathrm{MC}, \mathrm{Li} \mathrm{AF}, \mathrm{Wu} \mathrm{CW}$ and Chiou SH: Microsatellite instability is associated with a better prognosis for gastric cancer patients after curative surgery. World J Surg 36: 2131-2138, 2012.

5 Cancer Genome Atlas Research Network: Comprehensive molecular characterization of gastric adenocarcinoma. Nature 513: 202-209, 2014.

6 Huarte M, Guttman M, Feldser D, Garber M, Koziol MJ, Kenzelmann-Broz D, Khalil AM, Zuk O, Amit I, Rabani M, Attardi LD, Regev A, Lander ES, Jacks T and Rinn JL: A large intergenic noncoding RNA induced by p53 mediates global gene repression in the p53 response. Cell 142: 409-419, 2010.

7 Liu Y, Chen C, Xu Z, Scuoppo C, Rillahan CD, Gao J, Spitzer B, Bosbach B, Kastenhuber ER, Baslan T, Ackermann S, Cheng L, Wang Q, Niu T, Schultz N, Levine RL, Mills AA and Lowe SW: Deletions linked to TP53 loss drive cancer through p53independent mechanisms. Nature 531: 471-475, 2016.

8 Du X, Chen Z, Li W, Tan Y, Lu J, Zhu X, Zhao T, Dong G and Zeng L: Development of novel microsatellite DNA markers by cross-amplification and analysis of genetic variation in gerbils. J Hered 101: 710-716, 2010.

9 Umar A, Boland CR, Terdiman JP, Syngal S, de la Chapelle A, Ruschoff J, Fishel R, Lindor NM, Burgart LJ, Hamelin R, Hamilton SR, Hiatt RA, Jass J, Lindblom A, Lynch HT, Peltomaki P, Ramsey SD, Rodriguez-Bigas MA, Vasen HF, Hawk ET, Barrett JC, Freedman AN and Srivastava S: Revised Bethesda Guidelines for hereditary nonpolyposis colorectal cancer (Lynch syndrome) and microsatellite instability: J Natl Cancer Inst 96: 261-268, 2004.

10 Hahn M, Fislage R and Pingoud A: Polymorphism of the pentanucleotide repeat d(AAAAT) within intron 1 of the human tumor suppressor gene p53 (17p13.1). Hum Genet 95: 471-472, 1995.

11 Kamat N, Khidhir MA, Jaloudi M, Hussain S, Alashari MM, Al Qawasmeh KH and Rannug U: High incidence of microsatellite instability and loss of heterozygosity in three loci in breast cancer patients receiving chemotherapy: a prospective study. BMC Cancer 12: 1471-2407, 2012.

12 Lee HS, Choi SI, Lee HK, Kim HS, Yang HK, Kang GH, Kim YI, Lee BL and Kim WH: Distinct clinical features and outcomes of gastric cancers with microsatellite instability. Mod Pathol 15: 632-640, 2002. 
13 Kim TM, Laird PW and Park PJ: The landscape of microsatellite instability in colorectal and endometrial cancer genomes. Cell 155: 858-868, 2013.

14 Kim JG, Sohn SK, Chae YS, Song HS, Kwon KY, Do YR, Kim MK, Lee KH, Hyun MS, Lee WS, Sohn CH, Jung JS, Kim GC, Chung HY and Yu W: TP53 codon 72 polymorphism associated with prognosis in patients with advanced gastric cancer treated with paclitaxel and cisplatin. Cancer Chemother Pharmacol 64: 355-360, 2009.

15 Zha Y, Gan P, Liu Q and Yao Q: TP53 Codon 72 Polymorphism Predicts Efficacy of Paclitaxel Plus Capecitabine Chemotherapy in Advanced Gastric Cancer Patients. Arch Med Res 47: 13-18, 2016.

16 Henriquez-Hernandez LA, Murias-Rosales A, GonzalezHernandez A, de Leon AC, Diaz-Chico N and Fernandez-Perez L: Distribution of TYMS, MTHFR, p53 and MDR1 gene polymorphisms in patients with breast cancer treated with neoadjuvant chemotherapy. Cancer Epidemiol 34: 634-638, 2010.
17 Chang MT, Asthana S, Gao SP, Lee BH, Chapman JS, Kandoth C, Gao J, Socci ND, Solit DB, Olshen AB, Schultz N and Taylor BS: Identifying recurrent mutations in cancer reveals widespread lineage diversity and mutational specificity. Nat Biotechnol 34: 155-163, 2016.

18 Brosh R and Rotter V: When mutants gain new powers: news from the mutant p53 field. Nat Rev Cancer 9: 701-713, 2009.

19 Oren $\mathrm{M}$ and Rotter V: Mutant p53 gain-of-function in cancer. Cold Spring Harb Perspect Biol 2: a001107, 2010.
Received June 8, 2017

Revised June 23, 2017

Accepted June 26, 2017 